\title{
Article \\ Precision Medicine into Clinical Practice: A Web-Based Tool Enables Real-Time Pharmacogenetic Assessment of Tailored Treatments in Psychiatric Disorders
}

\author{
Stefania Zampatti ${ }^{1,+}$, Carlo Fabrizio $^{1,+}{ }^{+}$, Michele Ragazzo ${ }^{2}$, Giulia Campoli ${ }^{1}$, Valerio Caputo ${ }^{2}{ }^{(D}$,

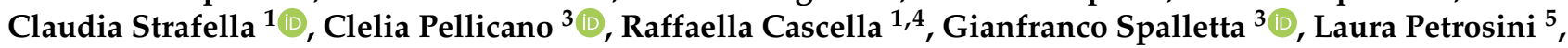 \\ Carlo Caltagirone ${ }^{6}$, Andrea Termine ${ }^{1, \ddagger}$ (i) and Emiliano Giardina ${ }^{1,2, *, \ddagger}$
}

Citation: Zampatti, S.; Fabrizio, C.; Ragazzo, M.; Campoli, G.; Caputo, V.; Strafella, C.; Pellicano, C.; Cascella, R.; Spalletta, G.; Petrosini, L.; et al. Precision Medicine into Clinical Practice: A Web-Based Tool Enables Real-Time Pharmacogenetic Assessment of Tailored Treatments in Psychiatric Disorders. J. Pers. Med. 2021, 11, 851. https://doi.org/ 10.3390/jpm11090851

Academic Editor: Alan L. Myers

Received: 21 July 2021

Accepted: 24 August 2021

Published: 27 August 2021

Publisher's Note: MDPI stays neutral with regard to jurisdictional claims in published maps and institutional affiliations.

Copyright: (c) 2021 by the authors. Licensee MDPI, Basel, Switzerland. This article is an open access article distributed under the terms and conditions of the Creative Commons Attribution (CC BY) license (https:// creativecommons.org/licenses/by/ $4.0 /)$.
1 Genomic Medicine Laboratory UILDM, IRCCS Fondazione Santa Lucia, 00179 Rome, Italy; s.zampatti@hsantalucia.it (S.Z.); carlo.fabrizio217@gmail.com (C.F.); giuliacampoli90@gmail.com (G.C.); claudia.strafella@gmail.com (C.S.); raffaella.cascella@gmail.com (R.C.); andreatermine544@gmail.com (A.T.)

2 Department of Biomedicine and Prevention, Tor Vergata University of Rome, 00133 Rome, Italy; michele.ragazzo@uniroma2.it (M.R.); v.caputo91@gmail.com (V.C.)

3 Laboratory of Neuropsychiatry, Department of Clinical and Behavioral Neurology, IRCCS Santa Lucia Foundation, 00179 Rome, Italy; c.pellicano@hsantalucia.it (C.P.); g.spalletta@hsantalucia.it (G.S.)

4 Department of Biomedical Sciences, Catholic University Our Lady of Good Counsel, 1000 Tirana, Albania

5 Department of Experimental Neuroscience, IRCCS Fondazione Santa Lucia, 00143 Rome, Italy; laura.petrosini@uniroma1.it

6 Department of Clinical and Behavioral Neurology, IRCCS Fondazione Santa Lucia, 00179 Rome, Italy; c.caltagirone@hsantalucia.it

* Correspondence: emiliano.giardina@uniroma2.it

+ These authors share the 1st authorship.

$\ddagger$ These authors share the senior authorship.

\begin{abstract}
The management of neuropsychiatric disorders involves different pharmacological treatments. In order to perform efficacious drug treatments, the metabolism of CYP genes can help to foresee potential drug-drug interactions. The NeuroPGx software is an open-source web-based tool for genotype/diplotype/phenotype interpretation for neuropharmacogenomic purposes. The software provides information about: (i) the genotypes of evaluated SNPs (single nucleotide polymorphisms); (ii) the main diplotypes in CYP genes and corresponding metabolization phenotypes; (iii) the list of neuropsychiatric drugs with recommended dosage adjustment (according to CPIC and DPWG guidelines); (iv) the list of possible (rare) diplotypes and corresponding metabolization phenotypes. The combined application of NeuroPGx software to the OpenArray technology results in an easy, quick, and highly automated device ready to be used in routine clinical practice.
\end{abstract}

Keywords: neuroPGx; pharmacogenomic; software; OpenArray

\section{Introduction}

The advancement in treatment of diseases has allowed a great improvement in life quality and expectancy, with a demographic transition in the age of the population. Usually, the elderly suffers from chronic disorders (i.e., diabetes, hypertension, hypercholesterolemia and depressive disorder) with frequent comorbidities. Clinicians are aware of many potential drug-drug interactions (DDI) that are among the principal causes of adverse drug reactions (ADR). It is estimated that the DDI risk increases with the number of drugs administrated: from $13 \%$ in people with two concomitant drugs, to $38 \%$ with four concomitant drugs, till $82 \%$ with eight or more concomitant drugs [1,2].

The mechanisms of DDI and ADR involve the pharmacokinetic (PK) and pharmacodynamic (PD) pathways that are influenced by individual genomic differences. Many polymorphic variants have been identified to predict the individual response to drugs. A 
great number of variants have been found in genes coding for cytochromes responsible for drug metabolism and some ADR have been associated with specific HLA-haplotypes (i.e., HLA-B $57: 01$ in Abacavir ADR) [3]. To support the correct administration of drugs in clinical practice, several pieces of software have been developed so far (i.e., Epocrates, iFacts, Lexi-interact, Medscape, Micromedex) [4]. The genetic typing of polymorphisms associated with a differential cytochrome activity is a laboratory routine. Selected polymorphisms in CYP3A5, CYP2B6, CYP2C9, CYP2C19, and CYP2D6 genes can be genotyped to define alleles and diplotypes for prediction of enzyme activity. An ideal pharmacogenomic panel should investigate the least number of variants for the identification of the greatest number of alleles. Different technologies have been developed to improve the timing and the costs of this typing. In this scenario, genetic laboratories can perform the genetic typing for pharmacogenomic purposes with several different technologies (i.e., Real Time PCR, OpenArray, next-generation sequencing).

To improve the usefulness of the reported association between polymorphisms and drug effectiveness, several international consortia have published pharmacogenomics (PGx) guidelines. These guidelines reported pharmacologic adjustments recommended in patients with increased/reduced enzyme activity. The most widely used guidelines were developed by the Clinical Pharmacogenetics Implementation Consortium (CPIC) [5] and the Dutch Pharmacogenetics Working Group (DPWG) [6]. These guidelines are based on a systematic review of the available literature. In CPIC and DPWG guidelines, haplotype in CYP genes (coding for cytochromes) associated with a major/minor enzyme activity are reported with a specific suggestion for drug administration. From this perspective, the guidelines were developed as useful instruments supporting clinicians in pharmacologic treatment. Unfortunately, the reported recommendations may be dissimilar in different guidelines [7]. Furthermore, sometimes administration suggestions included in drug labels are discordant with what is reported in the guidelines [8].

The treatment of neuropsychiatric disorders often requires multi-drug administration. Furthermore, the high frequency of reduced compliance in neurological patients led to the need for a rapid PGx panel to improve the optimization times of drug treatment.

The vast majority of genetic analyses are performed through DNA sequencing. This approach can be carried out by sequencing a subset of genes specifically included in a custom panel (target resequencing) or by analyzing the entire exome. The cost reduction at the moment allows the routine use of the exome analysis and the standardization of the analyses, avoiding the development and validation of specific panels. However, the amount of data generated makes the interpretation phase challenging and virtual filters have been proposed that limit the interpretation to the genes of interest only. Alongside the sequencing platforms, a useful approach in many contexts is the genotyping, the genetic analysis limited to single specific polymorphisms. There are many massive genotyping platforms on the market capable of analyzing over a million polymorphisms. These approaches have been used successfully for GWAS, but their use in genetic diagnostics is limited. We believe that the genotyping platform could be an excellent tool in some areas of genetic diagnostics such as pharmacogenetics.

In this paper, we aimed at describing an integrated NeuroPGx system for the rapid evaluation of samples for neuropsychiatric-pharmacogenomic purposes. The automated genotyping (NeuroPGx panel) is followed by software data analysis and drug administration suggestion (NeuroPGx software), in order to provide useful information in about five hours from the sample collection (Figure 1). 


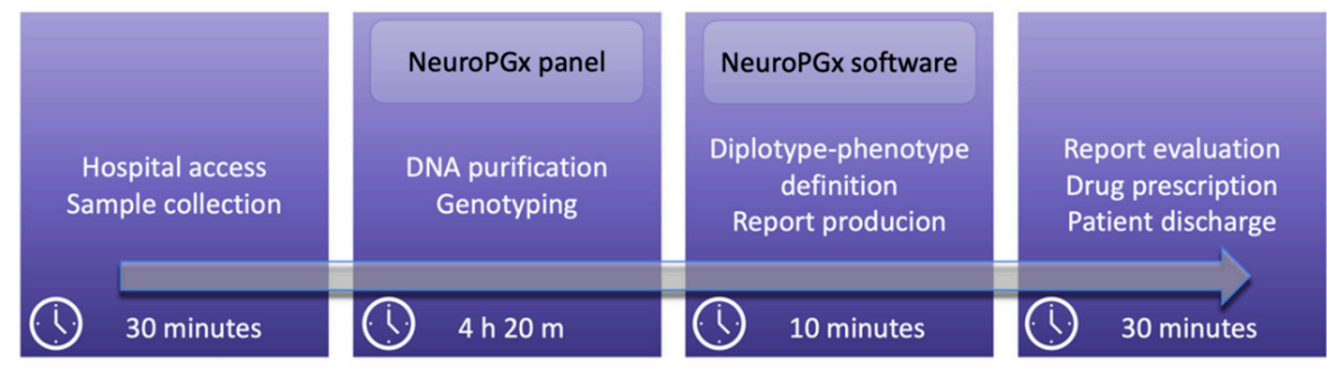

Figure 1. Application model of NeuroPGx system in clinical practice. Excluding the time of admission, clinical visit, and discharge of patients that are highly variable in different clinical centers, the overall time needed by NeuroPGx system is $4 \mathrm{~h} 30 \mathrm{~m}$.

OpenArray $^{\mathrm{TM}}$ technology is an easy and quick automated system for high-throughput genotyping. In particular, OpenArray is a nanofluidic real-time PCR system that utilizes a stainless steel, microscopic-scale plate with 384 wells, where TaqMan Assays are spotted according to customer specifications. The plate design allows for the genotyping of several samples in a unique experiment. In fact, the system can process one to four QuantStudio 12K Flex OpenArray plates simultaneously, in order to genotype over 1700 samples in a day.

Similar to what happens in genetic sequencing analyzes, we applied the concept of virtual interpretation panels to genotyping.

The TaqMan ${ }^{\circledR}$ OpenArray ${ }^{\circledR}$ Pharmacogenomics (PGx) Panel analyzes a large number of polymorphisms, but the interpretation is limited only to those of interest for neuropharmacogenomic purposes to reduce the analysis and reporting times. In particular, out of the 60 polymorphisms in 14 genes, 39 SNPs in 5 genes were selected for their known role in the metabolism of neurological drugs. Table 1 summarizes polymorphic variants selected for neuropharmacogenomic (NeuroPGx panel) OpenArray ${ }^{\mathrm{TM}}$ panel.

Table 1. NeuroPGx panel (based on OpenArray ${ }^{\mathrm{TM}}$ technology).

\begin{tabular}{|c|c|c|c|c|c|c|c|}
\hline GENEs & HGVS & Alleles ${ }^{1}$ & $\begin{array}{c}\text { Major } \\
\text { Nucleotide } \\
\text { Variation }\end{array}$ & RS ID & AssayID & $\begin{array}{l}\text { Nucleotide } \\
\text { Change }\end{array}$ & Effect on Protein \\
\hline \multirow{3}{*}{ CYP2B6 } & \multirow{3}{*}{$\begin{array}{l}\text { NC_000019; } \\
\text { NG_007929.1; } \\
\text { NM_000767; } \\
\text { NP_000758.1 }\end{array}$} & $* 22, * 34, * 35, * 36$ & $-82 \mathrm{~T}>\mathrm{C}$ & rs34223104 & C_27830964_10 & g. $40991224 \mathrm{~T}>\mathrm{C}$ & $\begin{array}{c}\text { Upstream Transcript } \\
\text { Variant }\end{array}$ \\
\hline & & $\begin{array}{l}* 16,{ }^{*} 18 \\
* 5, * 7\end{array}$ & $\begin{array}{c}983 \mathrm{~T}>\mathrm{C} \\
25505 \mathrm{C}>\mathrm{T}\end{array}$ & $\begin{array}{l}\text { rs28399499 } \\
\text { rs3211371 }\end{array}$ & $\begin{array}{l}\text { C__60732328_20 } \\
\text { C__30634242_40 }\end{array}$ & $\begin{array}{l}\text { c. } 983 \mathrm{~T}>\mathrm{C} \\
\text { c. } 1459 \mathrm{C}>\mathrm{T}\end{array}$ & $\begin{array}{l}\text { p.Ile328Thr } \\
\text { p.Arg487Cys }\end{array}$ \\
\hline & & *17 & $-806 \mathrm{C}>\mathrm{T}$ & rs12248560 & C___469857_10 & $-806 \mathrm{C}>\mathrm{T}$ & $\begin{array}{c}\text { Upstream Transcript } \\
\text { Variant }\end{array}$ \\
\hline \multirow{8}{*}{ CYP2C19 } & \multirow{7}{*}{$\begin{array}{l}\text { NC_000010; } \\
\text { NG_055436; } \\
\text { NM_000769; } \\
\text { NP_000760 }\end{array}$} & $* 4 \mathrm{~A} / \mathrm{B}$ & $1 \mathrm{~A}>\mathrm{G}$ & rs28399504 & C__30634136_10 & c. $1 \mathrm{~A}>\mathrm{G}$ & p.Met1Leu \\
\hline & & *8 & $12711 \mathrm{~T}>\mathrm{C}$ & rs41291556 & C__30634130_30 & c. $358 \mathrm{~T}>\mathrm{C}$ & p.Trp120Arg \\
\hline & & $* 6$ & $12748 \mathrm{G}>\mathrm{A}$ & rs72552267 & C__27531918_10 & c. $395 \mathrm{G}>\mathrm{A}$ & p.Arg132Gln \\
\hline & & *9 & $12784 \mathrm{G}>\mathrm{A}$ & rs17884712 & C_-25745302_30 & c. $431 \mathrm{G}>\mathrm{A}$ & p.Arg144His \\
\hline & & $* 3$ & $17948 \mathrm{G}>\mathrm{A}$ & rs4986893 & C__27861809_10 & c. $636 \mathrm{G}>\mathrm{A}$ & p.Trp212Ter \\
\hline & & *10 & $19153 \mathrm{C}>\mathrm{T}$ & rs6413438 & C_30634128_10 & $19153 \mathrm{C}>\mathrm{T}$ & p.Pro227Leu \\
\hline & & $* 2$ & $19154 \mathrm{G}>\mathrm{A}$ & rs4244285 & C__25986767_70 & $\begin{array}{c}\text { c. } 681 \mathrm{G}> \\
\mathrm{A} / 19154 \mathrm{G}>\mathrm{A}\end{array}$ & p.Pro227 = \\
\hline & \multirow{8}{*}{$\begin{array}{l}\text { NC_000010; } \\
\text { NG_008385; } \\
\text { NM_000771; } \\
\text { NP_000762 }\end{array}$} & $* 7$ & $19294 \mathrm{~T}>\mathrm{A}$ & rs72558186 & C__30634127_10 & g. $94781999 \mathrm{~T}>\mathrm{A}$ & Splice Donor Variant \\
\hline \multirow{7}{*}{ СYР2C9 } & & $* 5$ & $90033 \mathrm{C}>\mathrm{T}$ & rs56337013 & C__27861810_10 & c. $1297 \mathrm{C}>\mathrm{T}$ & p.Arg433Trp \\
\hline & & $* 2,{ }^{*} 35,{ }^{*} 61$ & $3608 \mathrm{C}>\mathrm{T}$ & rs1799853 & C__25625805_10 & c. $430 \mathrm{C}>\mathrm{T}$ & p.Arg144Cys \\
\hline & & $* 6$ & 10601delA & $\begin{array}{c}\text { rs9332131; } \\
\text { hcv32287221 }\end{array}$ & C_32287221_20 & c.818delA & p.Lys273ArgfsTer34 \\
\hline & & $* 11$ & $42542 \mathrm{C}>\mathrm{T}$ & rs28371685 & C__30634132_70 & c. $1003 \mathrm{C}>\mathrm{T}$ & p.Arg335Trp \\
\hline & & $* 3, * 18$ & $42614 \mathrm{~A}>\mathrm{C}$ & rs1057910 & C__27104892_10 & c. $1075 \mathrm{~A}>\mathrm{G}$ & p.Ile359Val \\
\hline & & ${ }^{*} 4$ & $42615 \mathrm{~T}>\mathrm{C}$ & rs56165452 & C__30634131_20 & c.1076T > C & p.Ile359Thr \\
\hline & & $* 5$ & $42619 C>G$ & rs28371686 & C__27859817_40 & c. $1080 \mathrm{C}>\mathrm{G}$ & p.Asp360Glu \\
\hline
\end{tabular}


Table 1. Cont.

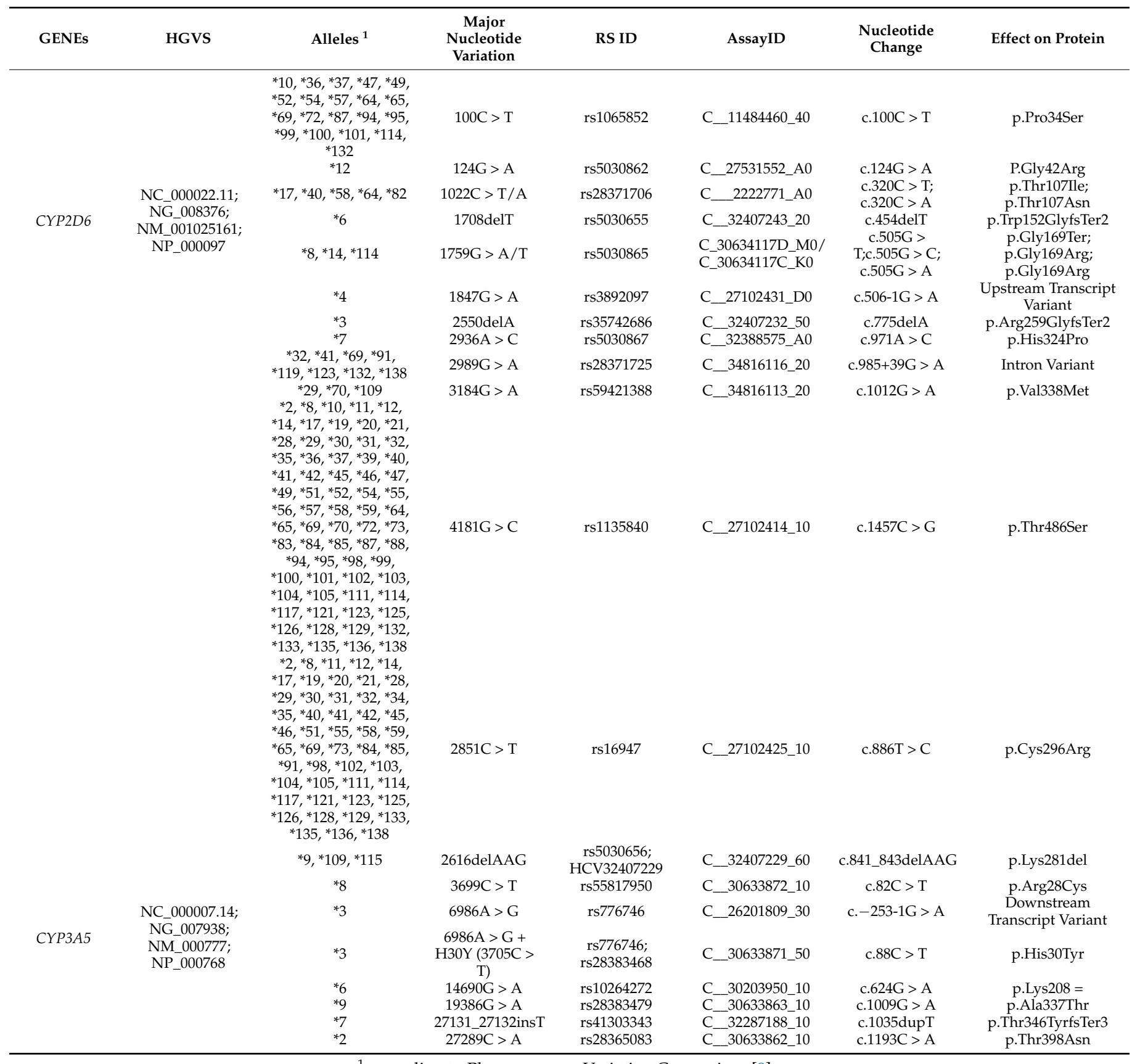

${ }^{1}$ according to Pharmacogene Variation Consortium [9].

In order to reduce the time for analysis, a user-friendly software for haplotype definition has been created. The NeuroPGx software is an open-source facility for genotype/diplotype/phenotype interpretation for neuroPGx purposes. It has been developed for the OpenArray ${ }^{\mathrm{TM}}$ NeuroPGx panel, but it can elaborate data from each genotyping platform.

\section{Materials and Methods}

\subsection{Selection of Drugs and CYP Variants}

Forty-seven neuropsychiatric drugs were selected for their metabolic association with CYP enzymes. One non-neurological drug (clopidogrel) has been added to the list of selected drugs due to its large use in clinical practice. The selected drugs and CYP genes associated with a different drug metabolism are summarized in Table 2. 
Table 2. Selected drugs and CYP genes associated.

\begin{tabular}{|c|c|c|}
\hline Drug & Genes $^{1}$ & References \\
\hline Agomelatine & CYP1A2, CYP2C9 & {$[10,11]$} \\
\hline Alprazolam & СYP2C19, CYP2C9, CYP3A4, СYP3A5, CYP3A7 & {$[10,12-14]$} \\
\hline Amitriptyline & CYP2D6, CYP2C19, CYP1A2, CYP2C9, CYP3A4 & {$[10,15]$} \\
\hline Aripiprazole & CYP2D6, CYP3A4 & {$[10,16,17]$} \\
\hline Atomoxetine & CYP2D6, CYP2C19 & {$[18,19]$} \\
\hline Bupropion & CYP2B6 & {$[10,15]$} \\
\hline Buspirone & CYP3A4 & {$[10,20]$} \\
\hline Carbamazepine & CYP1A2, CYP3A4, CYP3A5, CYP2C19, CYP2C8 & {$[10,21-23]$} \\
\hline Chlorpromazine & CYP2D6, CYP2C19, CYP1A2, CYP3A4 & {$[10,24-26]$} \\
\hline Citalopram & CYP2C19, CYP2D6, CYP3A4 & {$[10,15,27]$} \\
\hline Clobazam & CYP2C19, CYP3A, CYP2B6 & [28] \\
\hline Clomipramine & CYP2D6, CYP2C19, CYP1A2, CYP3A4 & {$[10,15]$} \\
\hline Clonazepam & CYP3A4, CYP3A5 & {$[10,29]$} \\
\hline Clopidogrel & CYP2C19 & [30] \\
\hline Clozapine & CYP1A2, CYP2D6, CYP3A4, CYP2C19 & {$[10,31]$} \\
\hline Desipramine & CYP1A2, CYP2D6 & {$[10,32,33]$} \\
\hline Desvenlafaxine & CYP2C19, CYP3A4 & [15] \\
\hline Doxepin & CYP2D6, CYP2C19, CYP2C9 & {$[10,15,34]$} \\
\hline Duloxetine & CYP1A2, CYP2D6 & {$[10,15,35]$} \\
\hline Escitalopram & CYP2C19, CYP2D6, CYP3A4 & {$[10,15,36]$} \\
\hline Fluoxetine & $\begin{array}{c}\text { CYP2D6, CYP1A2, CYP2B6, CYP2C9, CYP2C19, } \\
\text { CYP3A4, СYP3A5 }\end{array}$ & {$[10,37]$} \\
\hline Fluvoxamine & CYP2D6, CYP1A2 & {$[10,15,38]$} \\
\hline Haloperidol & CYP2D6, CYP3A4 & [39] \\
\hline Imipramine & CYP2D6, CYP2C19, CYP1A2, CYP3A4 & {$[10,15]$} \\
\hline Lurasidone & CYP $3 A 4$ & {$[10,15]$} \\
\hline Mirtazapine & CYP1A2, CYP2D6, CYP3A4, CYP2C19 & {$[10,15,40]$} \\
\hline Nortriptyline & CYP2D6, CYP1A2, CYP2C19, CYP3A4 & {$[10,33]$} \\
\hline Olanzapine & CYP1A2, CYP2D6 & {$[10,41]$} \\
\hline Oxcarbazepine & - & {$[10,42]$} \\
\hline Paroxetine & CYP2D6, CYP3A4 & {$[10,15]$} \\
\hline Perphenazine & CYP2D6 & {$[10,43]$} \\
\hline Phenytoin & CYP2C9, CYP2C19 & {$[44]$} \\
\hline Pimozide & CYP2D6, CYP3A4, CYP1A2 & {$[10,45]$} \\
\hline Quetiapine & CYP2D6, CYP3A4 & {$[10,15,46]$} \\
\hline Reboxetine & CYP $3 A 4$ & {$[10,15]$} \\
\hline Risperidone & CYP2D6 & {$[10,47,48]$} \\
\hline Sertraline & СYP2C19, СYP2B6, CYP2C9, CYP2D6, CYP3A4 & {$[10,15,49]$} \\
\hline Thioridazine & CYP2D6 & {$[10,50]$} \\
\hline Trazodone & CYP2D6, CYP3A4, CYP1A2 & {$[10,51]$} \\
\hline Trimipramine & CYP2C19, CYP2C9, CYP2D6, CYP3A4 & {$[10,15,52]$} \\
\hline Valproic acid & CYP2A6, CYP2B6, CYP2C9, СYP2C19 & {$[10,53]$} \\
\hline Venlafaxine & CYP2C19, CYP2D6, CYP3A4 & {$[10,15,54]$} \\
\hline Vortioxetine & CYP3A4, CYP2C9, CYP2D6, CYP2C19 & {$[10,15,55]$} \\
\hline Ziprasidone & CYP3A4 & {$[10,56,57]$} \\
\hline Zolpidem & CYP1A2, CYP2D6, CYP3A4 & {$[10,58]$} \\
\hline Zonisamide & CYP3A4, CYP2C19 & {$[59,60]$} \\
\hline Zuclopenthixol & CYP2D6, CYP3A4 & {$[10,43,61]$} \\
\hline
\end{tabular}

${ }^{1}$ in bold genes which genotypes suggest a different drug administration, in italic genes associated with a different drug metabolism, but not included in guidelines [10].

From all CYP genes, CYP3A5, CYP2B6, CYP2C9, CYP2C19, and CYP2D6 were selected for their large representation in guidelines. Thirty-nine SNPs were selected in order to define haplotypes associated with differential enzyme activity at CYP3A5, CYP2B6, CYP2C9, CYP2C19, and CYP2D6. The selected SNPs and allele frequencies across populations [5] are summarized in Table 3. 


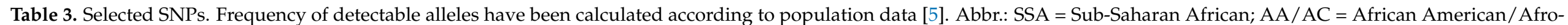
Carribbean; Eur = European; NE = Near Eastern; EA = East Asian; CSA = Central $/$ South Asian; Ame = American; Lat = Latino; Oce = Oceanian; AF = allele frequency.

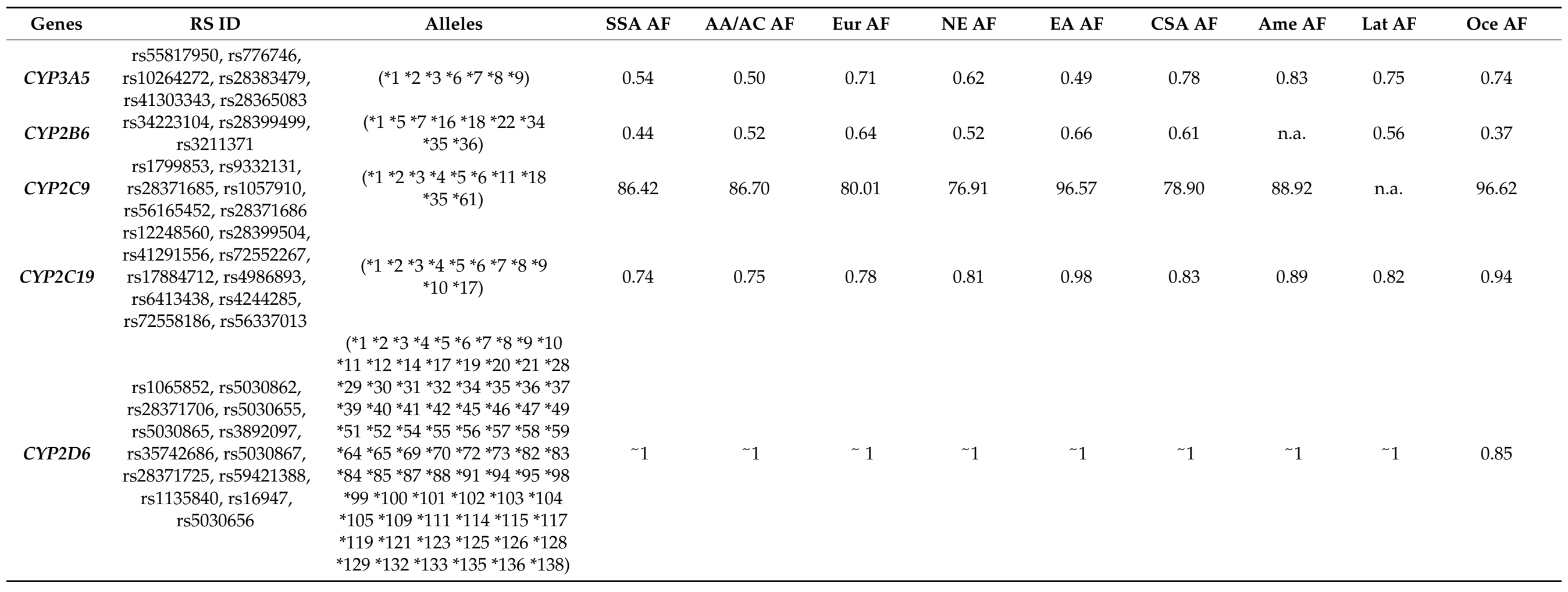




\subsection{DNA Purification and Quantification}

Genomic DNA was extracted from $400 \mu \mathrm{L}$ of peripheral blood using MagPurix Blood DNA Extraction Kit and MagPurix Automatic Extraction System (Resnova, Genzano di Roma, Rome, Italy) according to the manufacturer's instructions. The concentration and quality of the extracted DNA was checked by DeNovix Spectrophotometer (Resnova).

\subsection{OpenArray ${ }^{\mathrm{TM}}$ Technology}

The OpenArray ${ }^{\mathrm{TM}}$ Technology (Thermo Fisher Scientific, Waltham, MA, USA) is a high-throughput real-time PCR genotyping method that allows a rapid screening of several TaqMan assays in many samples. This real-time method involves the use of an array composed of 3072 through-holes running on QuantStudio 12K Flex Real Time PCR System (Thermo Fisher Scientific) with OpenArray ${ }^{\mathrm{TM}}$ block. The OpenArray ${ }^{\mathrm{TM}}$ system is composed of a specific plate (OpenArray ${ }^{\mathrm{TM}}$ plate) divided into 48 subarrays. The plate customized for this work consists of 60 probes pre-spotted in each of these 48 wells [62].

For each sample, $125-150 \mathrm{ng}$ of extracted DNA and $3 \mu \mathrm{L}$ of $2 \mathrm{X}$ TaqMan OpenArray ${ }^{\mathrm{TM}}$ Genotyping Master Mix were manually loaded into 384-well plates according to manufacturer's instructions (Thermo Fisher Scientific). Negative control was obtained by adding $3 \mu \mathrm{L}$ of pure distilled water to the Master Mix. The QuantStudio 12K Flex OpenArray ${ }^{\mathrm{TM}}$ AccuFill System transfers the previously generated mix to TaqMan OpenArray ${ }^{\mathrm{TM}}$ plate. The amplification is performed by QuantStudio 12K Flex Real Time PCR System (Thermo Fisher Scientific) instrument and the results have been analyzed by the Taqman Genotyper Software v1.3 and verified on Genotype app on Thermo Fisher Cloud (Thermo Fisher Scientific). For each SNP, the call rate was calculated through the Genotype app on Thermo Fisher Cloud.

\subsection{Statistical Analysis}

At the end of the analytical assay, the TaqMan Genotyper Software indicates the percentage of successful genotyping, reported as call rate. The call rate is defined as the fraction of SNPs that were assigned a genotype call by the software compared to the total number of SNPs typed. The successful call rate is defined as more than $90 \%$.

\subsection{NeuroPGx Software Designing}

Based on CPIC allele definition, an automated algorithm (NeuroPGx software) was created for the identification of diplotypes compatible with genotypes at selected SNPs. In particular, a user-friendly system was developed the genotype-diplotype definition for each CYP included in the neuroPGx panel. All possible diplotypes were evaluated for their enzymatic phenotype [9] and the frequency in the reference population [5].

The NeuroPGx software takes subjects' genotyping on five core genes (CYP2B6, CYP2C19, CYP2C9, CYP2D6, CYP3A5) as input and calculates all of the possible haplotype combinations, which are more than 5 million. As only a set of diplotypes are assignable to each subject based on their genotype, NeuroPGx outputs a table containing the possible diplotypes and highlights the most probable one based on population frequencies. Moreover, it reports genetic variation-associated drug metabolism profiles (Normal Metabolizer, Poor Metabolizer, Intermediate Metabolizer, Rapid Metabolizer, Ultrarapid Metabolizer). Finally, this information highlights CPIC and DWPG guidelines about drug use for the associated metabolism profiles [5-7].

\subsection{NeuroPGx Software Application}

NeuroPGx is written in R programming language (version 4.0.5) and the published interactive app is a dashboard made with Shiny (version 1.6.0) [63,64]. The application can be run locally or on a server. Running NeuroPGx requires installing the latest version of $R$ and Rstudio [64]. NeuroPGx is freely available on GitHub (https:/ / github.com/Andreater/ NeuroPGx, accessed on 20 August 2021) and it's released under the AGPLv3 license. 
Accessing GitHub (https:/ / github.com/Andreater/NeuroPGx, accessed on accessed on 20 August 2021) users can download the software and the instruction files, which are reported on the readme file of the repository. Extensive installation instructions are reported both on the readme and in the package homepage on GitHub. Users can find several examples of genotyping tables in the samples folder of the software (NeuroPGx/data/samples). The genotyping table is the input required to run NeuroPGx and it should contain all genotypes at selected SNPs (Table 3) for one or more samples. The input file can be prepared in an Excel spreadsheet with 4 columns: Sample, Gene, rsID, Genotype. Samples' ID should be reported in the Sample column while Gene Symbols and dbSNP IDs should fill the Gene and rsID columns. The Genotype column should be filled with genotype information for each sample and a "/" should be used as a separator. Deletions in a SNP can be coded as -/- or A/-, while more complex configurations, such as CTT/CTT, can be easily reported (Table S1). NeuroPGx also accepts .tsv and .csv files. If the genotyping table lacks some SNP or gene, the NeuroPGx will evaluate possible haplotype combinations based on the available data. When the app starts, it needs the genotyping table to be inputted by clicking on the "browse" button at the top left of the page (Figure 2). The elaboration starts and takes about 5-10 min to finish and show the output (Figure S1). The software page is divided into 6 panels. The "How it works" panel contains information about how to use the app. The "Samples" panel reports an interactive view of the input table, while the "Assigned diplotypes" panel shows an interactive view of the output table. The "Plots" panel shows plots for both the phenotype and the EHR, divided into two different tabs. The last two panels, namely "Suggested drug $w / o$ interaction" and "Suggested drug with interaction" summarize therapy adjustments based on CPIC and DWPG guidelines, as well as literature-retrieved indications. These suggestions are based on subject metabolic profiles without the interaction between genotypes and metabolites or with their interaction, respectively.

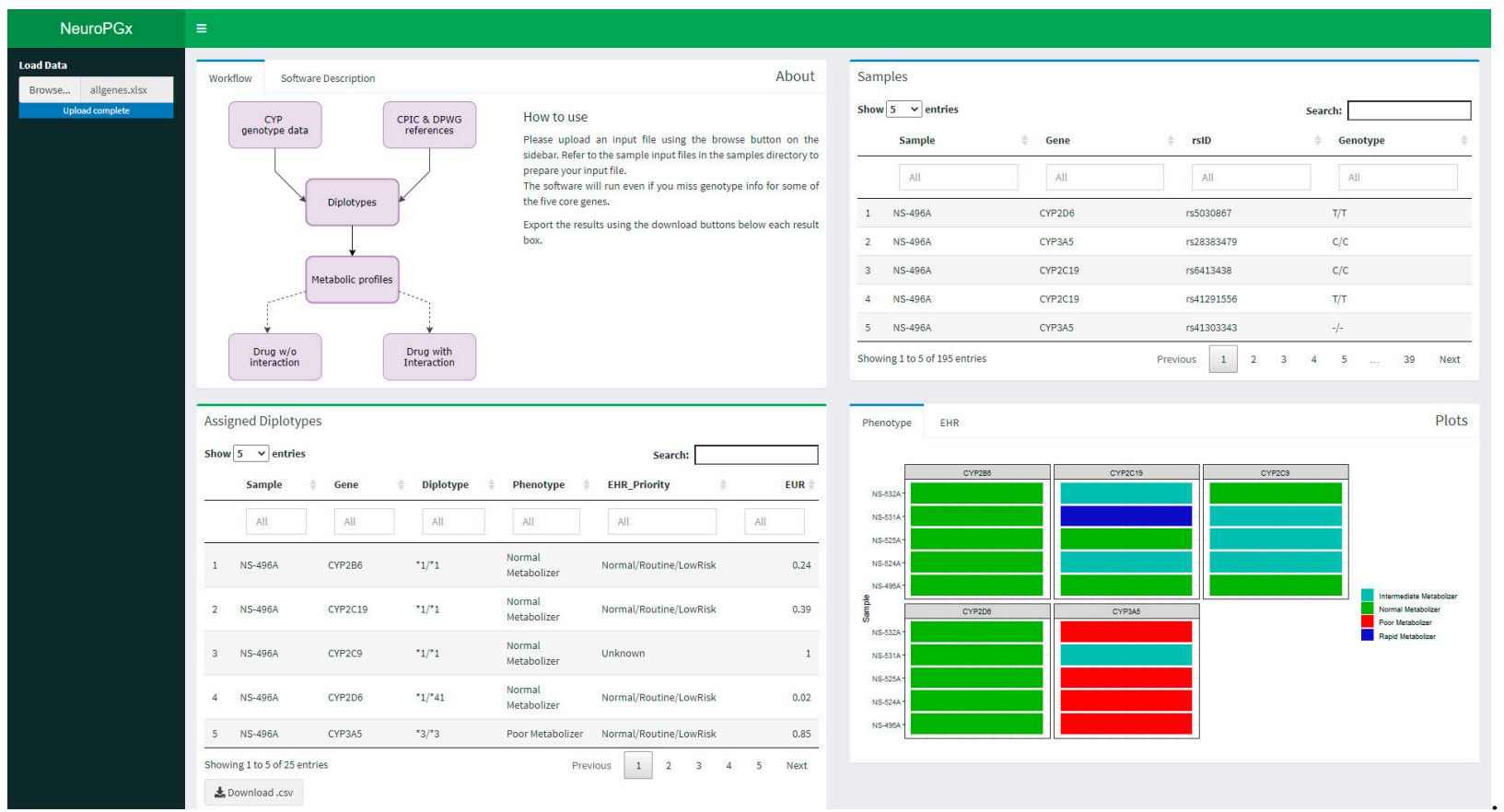

Figure 2. Overview of NeuroPGx software. On the top left, the user control menu. The four panels show: details about how the software works (up left), overview of uploaded samples and genotypes (up right), overview of assigned diplotypes (down left), rapid overview of metabolization profile (down right). Two other panels report guideline suggestions for sample metabolization profile (Figure S2). 


\section{Results}

A NeuroPGx system for the rapid pharmacogenomics evaluation of samples was developed and tested. Genotypes of SNPs involved in neuropsychiatric and neurological drug metabolisms (NeuroPGx Panel) were tested on 100 samples through the OpenArray platform, revealing an average call rate of $94.1 \%$. The Taqman Genotyper Software v1.3 on local computer devices and Genotype app on Thermo Fisher Cloud permit the analyzing of genotyping results. Thermo Fisher Cloud is an easy-to-use platform designed to support analyses and interpretation of instrumental results. In particular, Thermo Fisher Cloud gives figurative report of the OpenArray experiments, improving the interpretation and the quality evaluation time. The average call rate and allelic discrimination calls can be visualized in a condensed image that permits the evaluation of the quality of the experiment.

The development and application of NeuroPGx software permits the automated identification of all possible diplotypes compatible with genotypes at each CYP gene included in the virtual NeuroPGx Panel. Based on population characteristics, the software selects the most likely diplotype-phenotype (Table 3 and Figure 2). Otherwise, all possible diplotype-phenotype combinations are identified and listed in the final report. Therefore, the neuroPGx software report provides information about the: (i) genotypes at evaluated SNPs; (ii) main diplotypes at CYP genes and corresponding metabolization phenotypes; (iii) list of neuropsychiatric drugs with recommended dosage adjustment; (iv) list of possible (rare) diplotypes and corresponding metabolization phenotypes.

The application of NeuroPGx software to genotypic data allows one to obtain complete results for a single sample, for a pool of samples, and for samples with incomplete genotype information (i.e., if one gene and/or one SNP is missing). A complete README and "How to use" section on GitHub (https://github.com/Andreater/NeuroPGx, accessed on 20 August 2021) helps users to install and use the software. The software permits the analysis of samples even if the genotypic data are incomplete; detailed examples of how to build the input file (for one sample, for pool of samples, and if one gene/SNP is missing) are included on GitHub (https:/ / github.com/Andreater/NeuroPGx/tree/main/data/ samples, accessed on 20 August 2021).

\section{Discussion and Conclusions}

Here, we report the first NeuroPGx system ready for application in clinical practice. The exact interfacing between genotyping technologies and NeuroPGx software allows one to obtain results in a very short time. In particular, the application of virtual NeuroPGx Panel throughout OpenArray ${ }^{\mathrm{TM}}$ System to our new NeuroPGx software enables the full analysis (from sample to report) in about $4 \mathrm{~h}$ (Figure 1). It is well known that the time of analysis is often crucial in clinical practice and timely therapy of neuropsychiatric disorders can make all the difference. For this reason, the combination of a high-throughput and rapid technology such as OpenArray and the design of an automated interpretation system can improve the effectiveness of pharmacological therapy.

The NeuroPGx panel involves 39 SNPs for cytochrome enzymatic phenotypes' estimation and prevision of drug response. SNPs were selected from CPIC and DPWG guidelines for pharmacogenomic characterization of patients. These SNPs were tested on 100 samples, revealing an average call rate of $94.1 \%$. The OpenArray technology and the automated interpretation of results through Thermo Fisher Cloud reduce the analysis and interpretation times. In particular, the figurative report of the experiment permits a rapid evaluation of run quality. The evaluation of OpenArray technology confirms that it can easily detect genotypes at multiple loci, allowing one to obtain neuroPGx information in a short time. Compared with classical real-time PCR or with sequencing approaches, the OpenArray technology presents several advantages: it is quite fully automated, it is less time-consuming, and it is easy to analyze. Furthermore, the implementation of data in the Thermo Fisher Cloud facilitates the protection of experimental data from accidental loss. Moreover, the high rate of automated steps in sample processing permits the diffusion of this technology even in laboratories without a high expertise in molecular genetics. 
Although the processing optimization requires many samples (almost 16), the cost and time are really attractive. In particular, the NeuroPGx panel applied to OpenArray requires less than $4 \mathrm{~h}$ for analysis and about $20 \mathrm{~min}$ for interpretation.

The NeuroPGx software was designed to provide an automated interpretation of genotyping data that usually require a long time and are subject to human error. The NeuroPGx software is an open-source platform that provides a complete interpretation of genotyping data according to population distribution of compatible CYP alleles. In order to give an accurate and useful interpretation of genotypes, a full evaluation of administration details was performed on neuropsychiatric drugs (Table 2). As well as those of authorities in other countries [8], labels approved by the Food and Drug Administration (FDA), European Medicines Agency (EMA), and Italian Medicines Agency (AIFA) sometimes reported administration suggestions that are discordant with guideline recommendations (Table 4). Thus, the evaluation of cytochrome genotypes and metabolizing phenotypes in clinical practice should take into consideration suggestions of dosage adjustments in order to quickly identify the right dosage for the patient. For this reason, the PGx report provided by NeuroPGx software includes not only genetic data, but also administration recommendations according to the main international guidelines (CPIC and DPWG). Considering the well-known differences among suggestions in guidelines [7], the PGx report highlights all possible recommendations, in order to give complete information useful for clinicians (Figure S2).

Table 4. Comparison between guidelines (CPIC and DPWG) and drug labels (FDA and EMA/AIFA) for pharmacogenetic data. Abbr.: FDA = Food and Drug Administration; EMA = European Medicines Agency; AIFA = Italian Medicines Agency; noRec $=$ no recommendation reported in the guideline; $\mathrm{N}=$ no information about CYP phenotypes; $\mathrm{Y}=$ the label reports information about CYP phenotypes, with or without suggestion to investigate CYP genotype; NA: not approved.

\begin{tabular}{|c|c|c|c|c|c|}
\hline \multirow{2}{*}{ Drug } & \multirow{2}{*}{ Related Genes } & \multicolumn{2}{|c|}{ Indication in the Guidelines } & \multicolumn{2}{|c|}{ Label Indication } \\
\hline & & CPIC & DPWG & FDA & EMA/AIFA \\
\hline Agomelatine & & noRec & noRec & & \\
\hline Alprazolam & & noRec & noRec & & \\
\hline & CYP2D6 & & & Y & $\mathrm{Y}$ \\
\hline Amitriptyline & CYP2C19 & & & $\mathrm{N}$ & $\mathrm{Y}$ \\
\hline Aripiprazole & CYP2D6 & & & $\mathrm{Y}$ & $\mathrm{Y}$ \\
\hline Atomoxetine & CYP2D6 & & & $\mathrm{Y}$ & $\mathrm{Y}$ \\
\hline Bupropion & & noRec & noRec & & \\
\hline Buspirone & & noRec & noRec & & NA \\
\hline Carbamazepine & & noRec & noRec & & \\
\hline Chlorpromazine & & noRec & noRec & & \\
\hline Citalopram & CYP2C19 & & & $\mathrm{Y}$ & Y \\
\hline Clobazam & CYP2C19 & & & $\mathrm{Y}$ & $\mathrm{Y}$ \\
\hline Clomipramine & CYP2D6 & & & $\mathrm{Y}$ & $\mathrm{Y}$ \\
\hline Clonazepam & & noRec & noRec & & \\
\hline Clopidogrel & CYP2C19 & & & $\mathrm{Y}$ & $\mathrm{Y}$ \\
\hline Clozapine & & noRec & noRec & & \\
\hline Desipramine & & noRec & noRec & & NA \\
\hline Desvenlafaxine & & noRec & noRec & & NA \\
\hline Doxanin & CYP2D6 & & & $\mathrm{Y}$ & NA \\
\hline Doxepin & CYP2C19 & & & $\mathrm{N}$ & NA \\
\hline Duloxetine & & noRec & noRec & & \\
\hline Escitalopram & CYP2C19 & & & $\mathrm{Y}$ & $\mathrm{Y}$ \\
\hline Fluoxetine & CYP2D6 & & & $\mathrm{Y}$ & $\mathrm{Y}$ \\
\hline Fluvoxamine & CYP2D6 & & & $\mathrm{Y}$ & $\mathrm{N}$ \\
\hline Haloperidol & CYP2D6 & & & $\mathrm{N}$ & $\mathrm{N}$ \\
\hline
\end{tabular}


Table 4. Cont.

\begin{tabular}{|c|c|c|c|c|c|}
\hline \multirow{2}{*}{ Drug } & \multirow{2}{*}{ Related Genes } & \multicolumn{2}{|c|}{ Indication in the Guidelines } & \multicolumn{2}{|c|}{ Label Indication } \\
\hline & & CPIC & DPWG & FDA & EMA/AIFA \\
\hline & CYP2D6 & & & $\mathrm{Y}$ & NA \\
\hline Imıpramıne & CYP2C19 & & & $\mathrm{N}$ & NA \\
\hline Lurasidone & & noRec & noRec & & \\
\hline Mirtazapine & & noRec & noRec & & \\
\hline Nortriptyline & CYP2D6 & & & Y & $\mathrm{N}$ \\
\hline Olanzapine & & noRec & noRec & & \\
\hline Oxcarbazepine & & noRec & noRec & & \\
\hline Paroxetine & CYP2D6 & & & $\mathrm{Y}$ & $\mathrm{Y}$ \\
\hline Perphenazine & & noRec & noRec & & \\
\hline Phenytoin & CYP2C9 & & & $\mathrm{Y}$ & $\mathrm{Y}$ \\
\hline Pimozide & CYP2D 6 & & & $\mathrm{~N}$ & $\mathrm{~N}$ \\
\hline Quetiapine & & noRec & noRec & & \\
\hline Reboxetine & & noRec & noRec & & \\
\hline Risperidone & & noRec & noRec & & \\
\hline Sertraline & CYP2C19 & & & $\mathrm{N}$ & $\mathrm{Y}$ \\
\hline Thioridazine & & noRec & noRec & & NA \\
\hline Trazodone & & noRec & noRec & & \\
\hline Trimipramine & CYP2C19 & & & Y & $\mathrm{Y}$ \\
\hline Valproic acid & & noRec & noRec & & \\
\hline Venlafaxine & & noRec & noRec & & \\
\hline Vortioxetine & & noRec & noRec & & NA \\
\hline Ziprasidone & & noRec & noRec & & \\
\hline Zolpidem & & noRec & noRec & & \\
\hline Zonisamide & & noRec & noRec & & \\
\hline Zuclopenthixol & & noRec & noRec & & \\
\hline
\end{tabular}

To our knowledge, this is the first software that provides complete information from the genotype to the drug administration. Traditionally, interpretation tools help in defining metabolization profiles of selected CYP genes, without any reference to guidelines. The NeuroPGx software is designed to become a useful device in clinical practice; in fact, it is easy to use, it is applicable to data from all genotyping platforms, and it provides updated administration suggestions for all listed drugs.

In conclusion, the combined application of NeuroPGx software to the OpenArray technology results in an easy, quick, and highly automated device ready to be used in clinical practice. In particular, the quickness of this combination will help neurologists and psychiatrists in pharmacological therapy, giving important genetic information in about $4 \mathrm{~h}$. Considering time and costs of the NeuroPGx panel on the OpenArray platform, it is expected that analysis will allow one to obtain useful pharmacogenomic results (with a full genotype-phenotype and drugs report) in less than one working day. Taking into account the high frequency of reduced compliance and the necessity for multi-drug administration in the treatment of neuropsychiatric disorders, a rapid NeuroPGx system will permit the improvement of drug effectiveness. From this perspective, the validation of one-day pharmacogenomic test will promote its diffusion in clinical practice, supporting the precise administration of drugs. Furthermore, the NeuroPGx software by itself can be used to quickly define CYP metabolization profiles and guideline recommendations. Designed to meet the needs of psychiatrists, it will be extended to other pharmaceuticals fulfilling the needs of several specialties.

Supplementary Materials: The following are available online at https://www.mdpi.com/article/ 10.3390/jpm11090851/s1, Figure S1: Elaboration images, Figure S2: Full report, Table S1: List of genotypes recognized by the NeuroPgX software.

Author Contributions: Conceptualization, S.Z., A.T. and E.G.; methodology, S.Z., M.R. and E.G.; software, C.F., A.T. and V.C.; validation, S.Z., C.S. and R.C.; formal analysis, S.Z. and G.C.; data 
curation, S.Z., C.F., G.C., A.T. and R.C.; writing-original draft preparation, S.Z. and M.R.; writingreview and editing, S.Z., C.P., G.S., L.P., C.C. and E.G.; supervision, A.T., C.C. and E.G. All authors have read and agreed to the published version of the manuscript.

Funding: This work is also funded by the Italian Ministry of Health (5XMille-2018) and the National Research Council CNR (project "A multifactorial intervention for successful aging").

Institutional Review Board Statement: Not applicable.

Informed Consent Statement: Informed consent was obtained from all subjects involved in the study.

Data Availability Statement: The data generated in the present study are included within the manuscript and its supplementary file.

Conflicts of Interest: The authors declare no conflict of interest.

\section{References}

1. Goldberg, R.M.; Mabee, J.; Chan, L.; Wong, S. Drug-Drug and drug disease interactions in the ED: Analysis of a high-risk population. Am. J. Emerg. Med. 1996, 14, 447-450. [CrossRef]

2. Storelli, F.; Samer, C.; Reny, J.L.; Desmeules, J.; Daali, Y. Complex Drug-Drug-Gene-Disease Interactions Involving Cytochromes P450: Systematic Review of Published Case Reports and Clinical Perspectives. Clin. Pharmacokinet. 2018, 57, 1267-1293. [CrossRef] [PubMed]

3. Stocchi, L.; Cascella, R.; Zampatti, S.; Pirazzoli, A.; Novelli, G.; Giardina, E. The Pharmacogenomic HLA Biomarker Associated to Adverse Abacavir Reactions: Comparative Analysis of Different Genotyping Methods. Curr. Genom. 2012, 13, 314-320. [CrossRef] [PubMed]

4. Kheshti, R.; Aalipour, M.; Namazi, S. A comparison of five common drug-drug interaction software programs regarding accuracy and comprehensiveness. J. Res. Pharm. Pract. 2016, 5, 257-263. [PubMed]

5. Clinical Pharmacogenetics Implementation Consortium (CPIC). Available online: https:/ / cpicpgx.org/ (accessed on 20 June 2021).

6. Dutch Pharmacogenetics Working Group (DPWG). Available online: https://www.pharmgkb.org/page/dpwg/ (accessed on 20 June 2021).

7. Bank, P.C.D.; Caudle, K.E.; Swen, J.J.; Gammal, R.S.; Whirl-Carrillo, M.; Klein, T.E.; Relling, M.V.; Guchelaar, H.J. Comparison of the Guidelines of the Clinical Pharmacogenetics Implementation Consortium and the Dutch Pharmacogenetics Working Group. Clin. Pharmacol. Ther. 2018, 103, 599-618. [CrossRef]

8. Yoon, D.Y.; Lee, S.; Ban, M.S.; Jang, I.J.; Lee, S. Pharmacogenomic information from CPIC and DPWG guidelines and its application on drug labels. Transl. Clin. Pharmacol. 2020, 28, 189-198. [CrossRef] [PubMed]

9. Pharmacogene Variation Consortium. Available online: https://www.pharmvar.org/ (accessed on 20 June 2021).

10. Lozupone, M.; Panza, F.; Stella, E.; La Montagna, M.; Bisceglia, P.; Miscio, G.; Galizia, I.; Daniele, A.; di Mauro, L.; Bellomo, A.; et al. Pharmacogenetics of neurological and psychiatric diseases at older age: Has the time come? Expert Opin. Drug Metab. Toxicol. 2017, 13, 259-277. [CrossRef]

11. Saiz-Rodríguez, M.; Ochoa, D.; Belmonte, C.; Román, M.; Vieira de Lara, D.; Zubiaur, P.; Koller, D.; Mejía, G.; Abad-Santos, F. Polymorphisms in CYP1A2, CYP2C9 and ABCB1 affect agomelatine pharmacokinetics. J. Psychopharmacol. $2019,33,522-531$. [CrossRef]

12. Zhou, S.F.; Zhou, Z.W.; Yang, L.P.; Cai, J.P. Substrates, inducers, inhibitors and structure-activity relationships of human Cytochrome P450 2C9 and implications in drug development. Curr. Med. Chem. 2009, 16, 3480-3675. [CrossRef]

13. Gashaw, I.; Kirchheiner, J.; Goldammer, M.; Bauer, S.; Seidemann, J.; Zoller, K.; Mrozikiewicz, P.M.; Roots, I.; Brockmöller, J. Cytochrome p450 3A4 messenger ribonucleic acid induction by rifampin in human peripheral blood mononuclear cells: Correlation with alprazolam pharmacokinetics. Clin. Pharmacol. Ther. 2003, 74, 448-457. [CrossRef]

14. Williams, J.A.; Ring, B.J.; Cantrell, V.E.; Jones, D.R.; Eckstein, J.; Ruterbories, K.; Hamman, M.A.; Hall, S.D.; Wrighton, S.A. Comparative metabolic capabilities of CYP3A4, CYP3A5, and CYP3A7. Drug Metab. Dispos. 2002, 30, 883-891. [CrossRef] [PubMed]

15. Eap, C.B.; Gründer, G.; Baumann, P.; Ansermot, N.; Conca, A.; Corruble, E.; Crettol, S.; Dahl, M.L.; de Leon, J.; Greiner, C.; et al. Tools for optimising pharmacotherapy in psychiatry (therapeutic drug monitoring, molecular brain imaging and pharmacogenetic tests): Focus on antidepressants. World J. Biol. Psychiatry 2021, 12, 1-68. [CrossRef] [PubMed]

16. Bauman, J.N.; Frederick, K.S.; Sawant, A.; Walsky, R.L.; Cox, L.M.; Obach, R.S.; Kalgutkar, A.S. Comparison of the bioactivation potential of the antidepressant and hepatotoxin nefazodone with aripiprazole, a structural analog and marketed drug. Drug Metab. Metab. Dispos. 2008, 36, 1016-1029. [CrossRef] [PubMed]

17. Winans, E. Aripiprazole. Am. J. Health Syst. Pharm. 2003, 60, 2437-2445. [CrossRef] [PubMed]

18. Yu, G.; Li, G.F.; Markowitz, J.S. Atomoxetine: A Review of Its Pharmacokinetics and Pharmacogenomics Relative to Drug Disposition. J. Child. Adolesc. Psychopharmacol. 2016, 26, 314-326. [CrossRef] [PubMed]

19. Choi, C.I.; Bae, J.W.; Lee, Y.J.; Lee, H.I.; Jang, C.G.; Lee, S.Y. Effects of CYP2C19 genetic polymorphisms on atomoxetine pharmacokinetics. J. Clin. Psychopharmacol. 2014, 34, 139-142. [CrossRef] [PubMed] 
20. Foti, R.S.; Rock, D.A.; Wienkers, L.C.; Wahlstrom, J.L. Selection of alternative CYP3A4 probe substrates for clinical drug interaction studies using in vitro data and in vivo simulation. Drug Metab. Dispos. 2010, 38, 981-987. [CrossRef]

21. Djordjevic, N.; Milovanovic, D.D.; Radovanovic, M.; Radosavljevic, I.; Obradovic, S.; Jakovljevic, M.; Milovanovic, D.; Milovanovic, J.R.; Jankovic, S. CYP1A2 genotype affects carbamazepine pharmacokinetics in children with epilepsy. Eur. J. Clin. Pharmacol. 2016, 72, 439-445. [CrossRef]

22. Iannaccone, T.; Sellitto, C.; Manzo, V.; Colucci, F.; Giudice, V.; Stefanelli, B.; Iuliano, A.; Corrivetti, G.; Filippelli, A. Pharmacogenetics of Carbamazepine and Valproate: Focus on Polymorphisms of Drug Metabolizing Enzymes and Transporters. Pharmaceuticals 2021, 14, 204. [CrossRef]

23. Yoshimura, R.; Yanagihara, N.; Terao, T.; Minami, K.; Toyohira, Y.; Ueno, S.; Uezono, Y.; Abe, K.; Izumi, F. An active metabolite of carbamazepine, carbamazepine-10,11-epoxide, inhibits ion channel-mediated catecholamine secretion in cultured bovine adrenal medullary cells. Psychopharmacology 1998, 135, 368-373. [CrossRef]

24. Murray, M. Role of CYP pharmacogenetics and drug-drug interactions in the efficacy and safety of atypical and other antipsychotic agents. J. Pharm. Pharmacol. 2006, 58, 871-885. [CrossRef]

25. Xu, Q.; Wu, X.; Li, M.; Huang, H.; Minica, C.; Yi, Z.; Wang, G.; Shen, L.; Xing, Q.; Shi, Y.; et al. Association studies of genomic variants with treatment response to risperidone, clozapine, quetiapine and chlorpromazine in the Chinese Han population. Pharm. J. 2016, 16, 357-365. [CrossRef] [PubMed]

26. Wójcikowski, J.; Boksa, J.; Daniel, W.A. Main contribution of the cytochrome P450 isoenzyme 1A2 (CYP1A2) to N-demethylation and 5-sulfoxidation of the phenothiazine neuroleptic chlorpromazine in human liver-A comparison with other phenothiazines. Biochem Pharmacol. 2010, 80, 1252-1259. [CrossRef] [PubMed]

27. Bezchlibnyk-Butler, K.; Aleksic, I.; Kennedy, S.H. Citalopram-a review of pharmacological and clinical effects. J. Psychiatry Neurosci. 2000, 25, 241-254. [PubMed]

28. Tolbert, D.; Larsen, F. A Comprehensive Overview of the Clinical Pharmacokinetics of Clobazam. J. Clin. Pharmacol. 2019, 59, 7-19. [CrossRef] [PubMed]

29. Tóth, K.; Csukly, G.; Sirok, D.; Belic, A.; Kiss, Á.; Háfra, E.; Déri, M.; Menus, Á.; Bitter, I.; Monostory, K. Optimization of Clonazepam Therapy Adjusted to Patient's CYP3A Status and NAT2 Genotype. Int. J. Neuropsychopharmacol. 2016, 19, pyw083. [CrossRef]

30. Pereira, N.L.; Rihal, C.S.; So, D.Y.F.; Rosenberg, Y.; Lennon, R.J.; Mathew, V.; Goodman, S.G.; Weinshilboum, R.M.; Wang, L.; Baudhuin, L.M.; et al. Clopidogrel Pharmacogenetics. Circ. Cardiovasc. Interv. 2019, 12, e007811. [CrossRef]

31. Dean, L.; Kane, M. Clozapine Therapy and CYP Genotype. 2016 [updated 2021 May 26]. In Medical Genetics Summaries [Internet]; Pratt, V.M., Scott, S.A., Pirmohamed, M., Esquivel, B., Kane, M.S., Kattman, B.L., Malheiro, A.J., Eds.; National Center for Biotechnology Information (US): Bethesda, MD, USA, 2012.

32. Furman, K.D.; Grimm, D.R.; Mueller, T.; Holley-Shanks, R.R.; Bertz, R.J.; Williams, L.A.; Spear, B.B.; Katz, D.A. Impact of CYP2D6 intermediate metabolizer alleles on single-dose desipramine pharmacokinetics. Pharmacogenetics 2004, 14, 279-284. [CrossRef] [PubMed]

33. Hicks, J.K.; Sangkuhl, K.; Swen, J.J.; Ellingrod, V.L.; Müller, D.J.; Shimoda, K.; Bishop, J.R.; Kharasch, E.D.; Skaar, T.C.; Gaedigk, A.; et al. Clinical pharmacogenetics implementation consortium guideline (CPIC) for CYP2D6 and CYP2C19 genotypes and dosing of tricyclic antidepressants: 2016 update. Clin. Pharmacol. Ther. 2017, 102, 37-44. [CrossRef] [PubMed]

34. Kirchheiner, J.; Meineke, I.; Müller, G.; Roots, I.; Brockmöller, J. Contributions of CYP2D6, CYP2C9 and CYP2C19 to the biotransformation of E- and Z-doxepin in healthy volunteers. Pharmacogenetics 2002, 12, 571-580. [CrossRef]

35. Knadler, M.P.; Lobo, E.; Chappell, J.; Bergstrom, R. Duloxetine: Clinical pharmacokinetics and drug inter-actions. Clin. Pharmacokinet. 2011, 50, 281-294. [CrossRef] [PubMed]

36. Rao, N. The clinical pharmacokinetics of escitalopram. Clin. Pharmacokinet. 2007, 46, 281-290. [CrossRef]

37. Margolis, J.M.; O’Donnell, J.P.; Mankowski, D.C.; Ekins, S.; Obach, R.S. (R)-, (S)-, and racemic fluoxetine N-demethylation by human cytochrome P450 enzymes. Drug Metab. Dispos. 2000, 28, 1187-1191. [PubMed]

38. Hicks, J.K.; Bishop, J.R.; Sangkuhl, K.; Müller, D.J.; Ji, Y.; Leckband, S.G.; Leeder, J.S.; Graham, R.L.; Chiulli, D.L.; LLerena, A.; et al. Clinical Pharmacogenetics Implementation Consortium. Clinical Pharmacogenetics Implementation Consortium (CPIC) Guideline for CYP2D6 and CYP2C19 Genotypes and Dosing of Selective Serotonin Reuptake Inhibitors. Clin. Pharmacol. Ther. 2015, 98, 127-134. [CrossRef] [PubMed]

39. Prommer, E. Role of haloperidol in palliative medicine: An update. Am. J. Hosp. Palliat. Care. 2012, 29, 295-301. [CrossRef]

40. Anttila, S.A.; Leinonen, E.V. A review of the pharmacological and clinical profile of mirtazapine. CNS Drug Rev. 2001, 7, 249-264. [CrossRef]

41. Callaghan, J.T.; Bergstrom, R.F.; Ptak, L.R.; Beasley, C.M. Olanzapine. Pharmacokinetic and pharmacody-namic profile. Clin. Pharmacokinet. 1999, 37, 177-1793. [CrossRef]

42. Bang, L.; Goa, K. Oxcarbazepine: A review of its use in children with epilepsy. Paediatr. Drugs. 2003, 5, 557-573. [CrossRef] [PubMed]

43. Waade, R.B.; Solhaug, V.; Høiseth, G. Impact of CYP2D6 on serum concentrations of flupentixol, haloperidol, perphenazine and zuclopenthixol. Br. J. Clin. Pharmacol. 2021, 87, 2228-2235. [CrossRef] 
44. Fohner, A.E.; Rettie, A.E.; Thai, K.K.; Ranatunga, D.K.; Lawson, B.L.; Liu, V.X.; Schaefer, C.A. Associations of CYP2C9 and CYP2C19 Pharmacogenetic Variation with Phenytoin-Induced Cutaneous Adverse Drug Reactions. Clin. Transl. Sci. 2020, 13, 1004-1009. [CrossRef]

45. Chapron, B.D.; Dinh, J.C.; Toren, P.C.; Gaedigk, A.; Leeder, J.S. The Respective Roles of CYP3A4 and CYP2D6 in the Metabolism of Pimozide to Established and Novel Metabolites. Drug Metab. Dispos. 2020, 48, 1113-1120. [CrossRef] [PubMed]

46. DeVane, C.L.; Nemeroff, C.B. Clinical pharmacokinetics of quetiapine: An atypical antipsychotic. Clin. Pharmacokinet. 2001, 40, 509-522. [CrossRef]

47. Cui, Y.; Yan, H.; Su, Y.; Wang, L.; Lu, T.; Zhang, D.; Yue, W. CYP2D6 Genotype-Based Dose Recommendations for Risperidone in Asian People. Front. Pharmacol. 2020, 11, 936. [CrossRef] [PubMed]

48. Zhang, L.; Brown, S.J.; Shan, Y.; Lee, A.M.; Allen, J.D.; Eum, S.; de Leon, J.; Bishop, J.R. CYP2D6 Genetic Polymorphisms and Risperidone Pharmacokinetics: A Systematic Review and Meta-analysis. Pharmacotherapy 2020, 40, 632-647. [CrossRef] [PubMed]

49. Saiz-Rodríguez, M.; Belmonte, C.; Román, M.; Ochoa, D.; Koller, D.; Talegón, M.; Ovejero-Benito, M.C.; López-Rodríguez, R.; Cabaleiro, T.; Abad-Santos, F. Effect of Polymorphisms on the Pharmacokinetics, Pharmacodynamics and Safety of Sertraline in Healthy Volunteers. Basic Clin. Pharmacol. Toxicol. 2018, 122, 501-511. [CrossRef]

50. Berecz, R.; de la Rubia, A.; Dorado, P.; Fernández-Salguero, P.; Dahl, M.L.; LLerena, A. Thioridazine steady-state plasma concentrations are influenced by tobacco smoking and CYP2D6, but not by the CYP2C9 genotype. Eur. J. Clin. Pharmacol. 2003, 59, 45-50. [CrossRef] [PubMed]

51. Davis, M.P. Does trazodone have a role in palliating symptoms? Support. Care Cancer. 2007, 15, 221-224. [CrossRef]

52. Kirchheiner, J.; Müller, G.; Meineke, I.; Wernecke, K.D.; Roots, I.; Brockmöller, J. Effects of polymorphisms in CYP2D6, CYP2C9, and CYP2C19 on trimipramine pharmacokinetics. J. Clin. Psychopharmacol. 2003, 23, 459-466. [CrossRef]

53. Zhu, M.M.; Li, H.L.; Shi, L.H.; Chen, X.P.; Luo, J.; Zhang, Z.L. The pharmacogenomics of valproic acid. J. Hum. Genet. 2017, 62, 1009-1014. [CrossRef]

54. McAlpine, D.E.; Biernacka, J.M.; Mrazek, D.A.; O’Kane, D.J.; Stevens, S.R.; Langman, L.J.; Courson, V.L.; Bhagia, J.; Moyer, T.P. Effect of cytochrome P450 enzyme polymorphisms on pharmacokinetics of venlafaxine. Ther Drug Monit. 2011, 33, 14-20. [CrossRef]

55. Chen, G.; Højer, A.M.; Areberg, J.; Nomikos, G. Vortioxetine: Clinical Pharmacokinetics and Drug Interactions. Clin. Pharmacokinet. 2018, 57, 673-686. [CrossRef] [PubMed]

56. Prakash, C.; Kamel, A.; Cui, D.; Whalen, R.D.; Miceli, J.J.; Tweedie, D. Identification of the major human liver cytochrome P450 isoform(s) responsible for the formation of the primary metabolites of ziprasidone and prediction of possible drug interactions. Br. J. Clin. Pharmacol. 2000, 49 (Suppl. 1), 35S-42S. [CrossRef]

57. Beedham, C.; Miceli, J.J.; Obach, R.S. Ziprasidone metabolism, aldehyde oxidase, and clinical implications. J. Clin. Psychopharmacol. 2003, 23, 229-232. [CrossRef]

58. Pichard, L.; Gillet, G.; Bonfils, C.; Domergue, J.; Thénot, J.P.; Maurel, P. Oxidative metabolism of zolpidem by human liver cytochrome P450S. Drug Metab. Dispos. 1995, 23, 1253-1262. [PubMed]

59. Okada, Y.; Seo, T.; Ishitsu, T.; Wanibuchi, A.; Hashimoto, N.; Higa, Y.; Nakagawa, K. Population estimation regarding the effects of cytochrome P450 2C19 and 3A5 polymorphisms on zonisamide clearance. Ther. Drug. Monit. 2008, 30, 540-543. [CrossRef]

60. Saruwatari, J.; Ishitsu, T.; Nakagawa, K. Update on the Genetic Polymorphisms of Drug-Metabolizing Enzymes in Antiepileptic Drug Therapy. Pharmaceuticals 2010, 3, 2709-2732. [CrossRef] [PubMed]

61. Davies, S.J.; Westin, A.A.; Castberg, I.; Lewis, G.; Lennard, M.S.; Taylor, S.; Spigset, O. Characterisation of zuclopenthixol metabolism by in vitro and therapeutic drug monitoring studies. Acta Psychiatr. Scand. 2010, 122, 444-453. [CrossRef] [PubMed]

62. Broccanello, C.; Gerace, L.; Stevanato, P. QuantStudio ${ }^{\text {TM }} 12$ K Flex OpenArray ${ }^{\circledR}$ System as a Tool for High-Throughput Genotyping and Gene Expression Analysis. In Quantitative Real-Time PCR. Methods in Molecular Biology; Humana: New York, NY, USA, 2020; Volume 2065, pp. 199-208.

63. Chang, W.; Cheng, J.; Allaire, J.; Xie, Y.; McPherson, J. Shiny: Web application framework for R. R Package Version $2017,1,2017$.

64. R Core Team. R: A Language and Environment for Statistical Computing; R Foundation for Statistical Computing: Vienna, Austria, 2021. Available online: https:/ / www.R-project.org/ (accessed on 20 June 2021). 